\title{
Research on Tacit Knowledge-Sharing Willingness in Trust Perspective-Empirical Analysis on Communication Enterprises
}

\author{
C.Q. Ding \\ Business School, Hehai University \\ Nanjing, China
}

\author{
J. Xue \\ Library, Nanjing University of Posts and Telecommunications \\ Nanjing, China
}

\author{
J. Yuan \\ College of Foreign Studies, Guilin University of Electronic Technology
}

\begin{abstract}
The trust among organization members is an important factor influencing the tacit knowledge-sharing willingness. This paper studied the antecedents influencing the trust and the functional mechanism between trust and tacit knowledge-sharing willingness, which was based on the data of 213 copies of questionnaire from knowledge workers in communication enterprises with an empirical research through structural equation model. The results show that both affect- and institution-based trust among knowledge workers has a significant positive impact on tacit knowledge-sharing willingness while cognition-based trust insignificant; and instrumental ties, organizational fairness and affiliation is the antecedents influencing the trust.
\end{abstract}

Keywords--tacit knowledge; sharing willingness; trust, structural equation model; empirical analysis

\section{INTRODUCTION}

In the knowledge-based enterprises, knowledge is the foundation of an enterprise's competitive advantage and, ultimately, the primary driver of an enterprise's value. Knowledge involves explicit know ledge and tacit knowledge. In relation to explicit knowledge, the capture and sharing of tacit knowledge relies more on the individual's sharing willingness. A large number of researches have confirmed the relationship between the peers' tacit knowledge-sharing willingness and the peers' mutual-trust. For instance, Bock confirmed that trust helps individuals avoid or decrease various risks resulted from the knowledge-sharing with other coworkers, which imposes a favorable influence on tacit knowledge-sharing willingness [1]. Janowicz et al. reported that trust, respect and friendship have a favorable influence on the close relationship between peers [2]. Smedlund pointed out that the social network within the organization facilitates the sharing and transfer of tacit knowledge. This social network is based on the long-term interpersonal and co-working relationship, and sustained by the mutual trust between the organizational members [3].

Trust is dimensional. In the categorization of the interpersonal trust dimension, the scaling of McAllister is of great importance. He categorizes trust into affect-based trust and cognition-based trust [4]. Gillespie claimed that in most cases, the peers involved in knowledge sharing are not possibly familiar with each other. In this regard, the willingness of tacit knowledge-sharing behavior relies more on the institutional guarantee. Consequently, institution-based trust imposes a great influence on affect-based and cognition-based trust [5]. Fang et al. argued institution-based trust has a foundational importance in facilitating the tacit knowledge-sharing in an organization [6].

Currently, the research literature on the importance of tacit knowledge-sharing is insufficient. Most of the researches focus on one or two dimensions of trust [2, 7], and the focus on the factors influencing trust are given less attention. This paper, viewing trust as the mediating variable influencing tacit knowledge-sharing willingness, from the perspective of the three trust dimensions, studies the antecedent variables influencing trust and the importance of trust on tacit knowledge-sharing willingness. The primary goal is to provide beneficiary inspiration and reference for knowledge management practicing in the context of enterprises.

\section{THEORETICAL BASIS AND RESEARCH HYPOTHESIS}

\section{A. Trust and Tacit knowledge-sharing willingness}

McAlliser defines trust as "the extent to which a person is confided in, and willing to act on the basis of, the words, actions and decisions of another" [4]. Huang et al. found that trust increases the integral knowledge-sharing level in the organization, and reinforces the possibility for an individual to tackle problems by appealing to, capturing, assimilating and applying others' knowledge [8].This paper, from the perspective of personal interaction and institution, conceptualizes trust into cognition-, affect- and institution-based dimensions, among which cognition- and affect-based trust is frequently incorporated into interpersonal trust.

Affect-based trust will be formed through people's investment in emotions, expressing care and understanding [4]. The research of Nonaka et al. has shown that a closer interpersonal relationship makes people more inclined to act so as to benefit others[9]. 
Institution-based trust is the members' confidence in the expectation, strategy, technology, commercial competence and structural fairness in the context of organization. Institution-based is decided by the systematic efficiency and fairness in the framework of an organization. It plays a primary role in knowledge sharing, especially when the related contributors are unfamiliar with each other [10]. In the initial period or knowledge sharing, institution-based trust plays a decisive role, which inclines to foster individual's willingness of tacit knowledge-sharing, even when the cognition and affect between them is not mature [11]. From the above analysis, we propose the hypothesis:

H1a: The affect-based trust between the organization members will be positively associated with the tacit knowledge-sharing willingness.

H1b: The cognition-based trust between the organization members will be positively associated with the tacit knowledge-sharing willingness.

H1c: The institution-based trust between the organization members will be positively associated with the tacit knowledge-sharing willingness.

\section{B. The Social network relationship and interpersonal trust}

The social network theory categorizes relationship into instrumental ties and expressive ties [8]. With the interaction between them, trust was gradually fostered between the individuals. Instrumental ties and expressive ties will have a positive influence on the trust.

Instrumental ties are grounded in the workplace and formal working relationship. It will be formed between the groups with different background, professional fields and in different cultural environment [12]. Gibbons proposed that in the workplace, the relationship between the peers is mostly the overlap of instrumental ties and expressive ties [13].

When the instrumental ties are sustained between the individual and the peer, the acknowledgement of the individual's competence and citizenship is effectively transmitted and codified through the peer's interaction. Subsequently, the cognition-based trust between the two sides is established. Driven under the common benefit and target, an individual is more likely to obtain the peer's active help when he encounters difficult problems in the working process. Based on the affective recognition, the affect-based trust is further ignited and established. Accordingly,

H2a: The instrumental ties have a significant positive influence on cognition-based trust.

$\mathrm{H} 2 \mathrm{~b}$ : The instrumental ties have a significant positive influence on affect-based trust.

Likewise, friendship is a critical component of the expressive ties. An individual is inclined to confide in and establish affect-based trust with those coworkers who have offered friendship and help to them. Expressive ties are also cultivated in the working place. The two groups with expressive ties tend to show more homogeneity in terms of character, social status cultural background. Consequently, they hold similar attitude and opinion on specific problems.
When the work-related problems are concerned, cognition-based trust arises. Accordingly,

H2c: Expressive ties are positively associated with affect-based trust.

H2d: Expressive ties are positively associated with cognition-based trust.

\section{Organizational Fairness, affiliation and institution-based trust}

Organizational fairness refers to the fairness of institutions, disciplines and measures perceived by the individual within the framework of an organization [1]. In the view of psychological contract theory, Sharkie argued that organizational fairness facilitate the employee's trust on the organization and the knowledge-sharing willingness [14]. We propose that in the fair organizational environment, the individuals acknowledge the recognition and acclaim obtained from the organization-beneficiary behavior. This recognition will in turn be demonstrated in allocation and decision-making. In regard to speculation behavior, it will be disciplined. Accordingly,

H3a: Organizational fairness has a significant positive influence on institution-based trust.

Organizational affiliation refers to the sense of closeness between the members. It is demonstrated in the mutual concern and pro-social behavior. This affiliation is the key facilitator that organization members will offer help to each other [1]. We claim that in the context of knowledge-sharing, when they sense more organizational affiliation, the individuals are more inclined to be normalized. Consequently, the mutual help and altruistic behavior increases, and the speculation in knowledge-sharing decreases. The stronger sense of organizational affiliation reinforces the personal trust on the organization, and the individuals' institution-based trust on the organization is upgraded. Accordingly,

H3b: The organizational affiliation has a significant positive influence on institution-based trust.

\section{Relationship between affect-, cognition-and institution-based trust}

Ford argued that in the context of knowledge management, the precondition to facilitate the establishment and development of interpersonal trust is the establishment of institutional restraint and incentive mechanism. This action will upgrade the individual's trust on the organizational institution [11]. We claim that institution is an important guarantee to the establishing of trust in terms of interpersonal relationship. The stable and reliable organizational restraint and incentive mechanism will facilitate the interpersonal communication and knowledge-sharing. It will in turn create conditions for uplifting the mutual rational cognition and establishing the trust based on rational cognition.

H4a: Institution-based trust has a significant positive influence on cognition-based trust.

Based on research, McAllister proposed that cognition-based trust is positively associated with affect-based trust[4]. We claim that the favorable cognition-based trust will 
strengthen the interpersonal understanding and acknowledging, and consequently propel the development of affect-based trust.

H4b: Cognition-based trust has a significant positive influence on affect-based trust.

\section{PROCEDURE}

\section{A. Questionnaire and measures}

The measures in this paper involve three steps: experimental index extract, exchange between experts and pretest of small capacity sample data.

\section{B. Collection of small capacity samples}

We test the reliability through the collected small sample data, delete the unqualified items and propose the final questionnaire.

In collecting the small capacity samples, we visit three enterprises, distribute 100 copies of questionnaire, of which the effective recovery of 82 . We will propose the small capacity forecast based on the 82 recovery of questionnaire, and utilize CITC analysis and $\alpha$ reliability analysis. All variable's reliability coefficient is above 0.7 , indicating a favorable reliability of the questionnaire that meets the requirement of research.

\section{Collection of large samples}

In large-scale questionnaire, we distribute 300 copies of questionnaire, recover 256 copies, of which the $71 \%$ effective recovery rate with 213 effective questionnaires. The respondents of these questionnaires are mostly the knowledge type employees in communication enterprises.

\section{STATISTIC RESULTS}

We utilize structural equation model system AMOS7.0 as the analysis instrument, and Maximum likelihood (ML) for the testing of model fit.

\section{A. Measurement model}

We analyze the measurement model of the hypothesis, calculate the average variance extracted (AVE) and construct reliability of the latent variables through the standardized factor loading. The standardized factor loading of the variables ranges from 0.75 to 0.94 . The AVE ranges from 0.66 to 0.81 . This presents the convergent validity of the latent variables is ideal and feasible. The construct reliability ranges from 0.853 to 0.944 . This represents the ideal stability of the measurement model.

\section{B. Testing of discrimination validity}

Following the previous literature, the discrimination validity of latent variables will be tested. This paper tests the discrimination validity of the latent variables through the comparison of the square root of the AVE and the coefficient of correlation. The result represents all the discrimination validities of the latent variables have the ideal and feasible property to make distinguish.

\section{Fit evaluation}

In this paper, the fit evaluation of the hypothesis model engages 12 indexes, of which 10 represents ideal fit $(\chi 2=235.3$, $\mathrm{df}=177)$. The index GFI and AGFI has acceptable fit and a-bit-low-to-acceptability fit respectively. This represents that the hypothesis model is generally supported by fit testing.

\section{Structural model}

The hypothesis testing of the structural equation model in this paper is shown in Figure 1.

\section{V.CONCLUSION AND DISCUSSION}

\section{A. Conclusion}

In Figure 1, 8 paths (H1a,H1c,H2a,H2b,H3a,H3b,H4a,

$\mathrm{H} 4 \mathrm{~b})$ are supported by significance test, and 3 paths (H1b,H2c,H2d) are not supported.

(1) The hypothesis that expressive ties have a significant positive influence on affect- and cognition-based trust is insignificant, and $\mathrm{H} 2 \mathrm{c}$ and $\mathrm{H} 2 \mathrm{~d}$ are not supported. The reason may be that most of the respondents have been working for a short time (64\% with less-than-4-year working experience). The establishing and sustaining of expressive ties relies on emotions and friendship, as between relatives and close friends. This relationship is mostly bounded with blood kinship or gradually fostered over time. In consequence, the expressive ties between the employees are relatively weak. In addition, the responding enterprises are mostly privately-owned ones, where there is a more competitive working environment. Among the enterprises or even broadly in the society, it is a pervasive phenomenon to take an edge over others through competition. Accordingly, the employees treat the work-related expressive ties with extreme prudence. Most employees are defensive not to reveal private information to the coworkers. This tendency leads to the insufficiency of expressive ties in working place. That explains that expressive ties have an insignificant influence on affect- and cognition-based trust.

(2) In the analysis of the influence of trust on tacit knowledge-sharing willingness, $\mathrm{H} 1 \mathrm{~b}$ is not supported. The reason is that cognition-based trust is grounded in an individual's acknowledging of the trust recipient's performance and professional skills. When the trust recipient has the cognition-based trust, out of the intention of guarding personal competitive advantage, he/she will not incline to share his/her core-level tacit knowledge. That explains cognition-based trust has an insignificant influence on tacit knowledge-sharing willingness.

\section{B. Implications, limitations and further research}

This paper, from the perspective of trust, explores the influence of three dimensions of trust on the knowledge type employees' tacit knowledge-sharing willingness. This implication is suitable to provide the knowledge manager with practical guideline in the context of an enterprise.

(1) We confirm the important influence of affect-based trust on tacit knowledge-sharing. When an enterprise requires the employees to share knowledge, especially tacit knowledge, effort should be taken to foster the affect-based trust among employees. 
(2) In terms of the level of mutual confidence between employees, measures can be taken from the perspective of network relationship. In the context of enterprises, affect-based trust relies more on instrumental ties. Moreover, the cognition-based trust will also enhance the affect-based trust between employees.

(3) Based on the research of McAllister, Holste et al. [4], we augment another dimension of trust, i.e. institution-based trust. This indicates that enterprise can greatly improve the knowledge-sharing environment and institution, foster the employees' confidence in the enterprise's institution, so as to provide a foundation for the development of cognition-based and affect-based trust.

This paper certainly has some limitations.

(1)The sampling scope is limited. The samples are restrained to the employees in communication enterprises, while other sectors are not involved. Consequently, it unavoidably has some limitation. The further research is required to expand the industry scope of samples.

(2)This paper hasn't incorporated the demographic variables. The years of working experience and ages are too intensive among the samples. The further research can explore the divergence analysis of different categories of samples.

\section{ACKNOWLEDGEMENTS:}

The work described in this paper was partially supported by the Philosophy and social science research projects in Colleges and universities in Jiangsu (Grant No. 2014SJB025), the Foundation of Nanjing University of Posts and Telecommunications (Grant No. NYS212030).

\section{REFERENCES}

[1] Bock, G.W., Zmud, R.W. \& Kim, Y.G. et al., Behavioral intention formation in knowledge sharing: examining the roles of extrinsic motivators, social-psychological forces, and organizational climate. MIS Quarterly, 29(1), pp. 87-111, 2005.

[2] Janowicz-Panjaitan, M. \& Noorderhaven, N.G., Trust, calculation and inter-organizational learning of tacit knowledge: an organizational roles perspective. Organization Studies, 30(10), pp. 1021-1044, 2009.

[3] Smedlund, A., The knowledge system of a firm: social capital for explicit, tacit and potential knowledge. Journal of Knowledge Management, 12(10), pp. 63-77, 2008.

[4] McAllister, D.J., Affect- and cognition-based trust as foundations for interpersonal cooperation in organizations. Academy of Management Journal, 38(1), pp. 24-59, 1995.

[5] Gillespie, N., \& Dietz, G., Trust repair after an organization-level failure Academy of Management Review, 34(1), pp. 127-145, 2009.

[6] Fang, Y.H. \& Chiu, C.M., In justice we trust: Exploring knowledge-sharing continuance intentions in virtual communities of practice. Computers in Human Behavior, 26(2), pp. 235-246, 2010.

[7] Nonaka, I. \&Takeuchi, H., The knowledge creating company, Oxford University Press: New York, pp. 58-61, 1995.

[8] Huang, Q., Davison, R.M. \& Gu, J., The impact of trust, guanxi orientation and face on the intention of Chinese employees and managers to engage in peer-to-peer tacit and explicit knowledge sharing. Information Systems Journal, 21(6), pp. 557-577, 2011.

[9] Thomas-Hunt, M. C. \& Ogden, T.Y.\& Neale, M. A., Who's really sharing? Effects of social and expert status on knowledge exchange within groups. Management Science, 49(4), pp. 464-477, 2003.

[10] Semerciöz, F., Hassan, M. \& Aldemır, Z., An Empirical Study on the Role of Interpersonal and Institutional Trust in Organizational Innovativeness. International Business Research, 4(2), pp. 125, 2011.

[11] Ford, D., Trust and knowledge management: The key to success. Centre for Knowledge-based Enterprise Working Paper, pp. 01-08, 2001.

[12] Zhong, X., Huang, Q. \& Davison, R.M. et al., Empowering teams through social network ties. International Journal of Information Management, 32(3), pp. 209-220, 2012.

[13] Gibbons, D.E., Friendship and advice networks in the context of changing professional values. Administrative Science Quarterly, 49(2), pp. 238-262, 2004.

[14] Sharkie, R., Precariousness under the new Psychological contract: the effect on trust and the willingness to converse and share knowledge. Knowledge Management Research \& Practiee, 3, pp. 37-44, 2005.

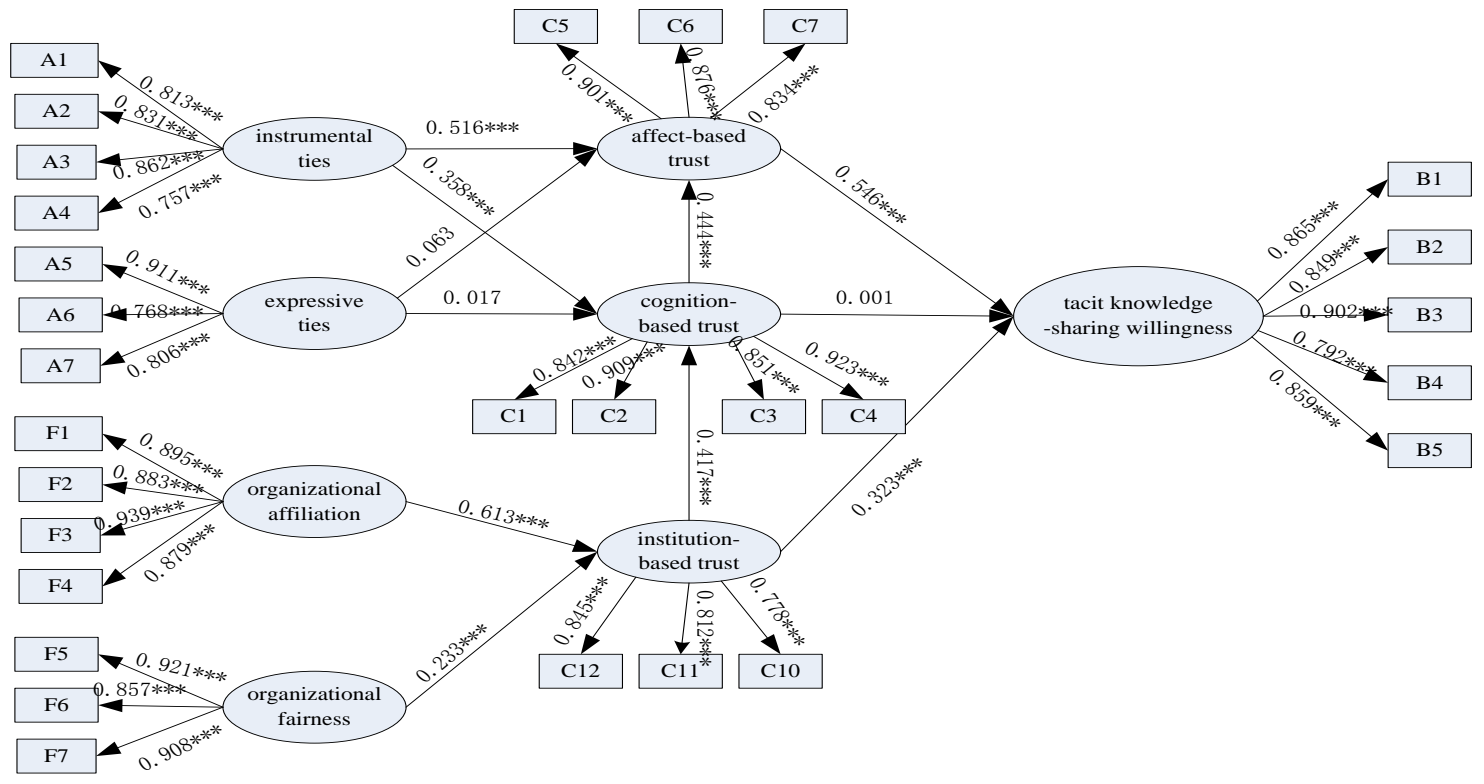

FIGURE I. THE INTEGRATED STRUCTURAL EQUATION MODEL, STANDARD COEFFICIENT: $* \mathrm{P} \leqslant 0.05 ; * * \mathrm{P} \leqslant 0.01 ; * * * \mathrm{P} \leqslant 0.001$. 